LA GRANA:

REVISTA DE

CIENCIAS DE LA VIDA

pISSN:1390-3799; eISSN:1390-8596

http:/ / doi.org/10.17163/lgr.n30.2019.10
Artículo científico / Scientific paper

DESARROLLO SOSTENIBLE

\title{
ANÁLISIS ESPACIAL DE LAS UNIDADES EDUCATIVAS DEL MILENIO EN EL ECUADOR Y SU COBERTURA EN ZONAS DE POBREZA
}

\author{
SPATIAL ANALYSIS OF EDUCATION MILLENNIUM UNITS IN ECUADOR AND \\ ITS COVERAGE OVER POVERTY AREAS
}

\author{
Gustavo Ernesto Navas*1 ${ }^{*}$, Robinson Llerena Paz ${ }^{1}{ }^{\infty}$ y Fernando Vaca ${ }^{2}$
}

${ }^{1}$ Carrera de Ingeniería de Sistemas, Universidad Politécnica Salesiana, Av. Moran Valverde y Rumichaca, Quito, Ecuador

${ }^{2}$ Grupo De Investigación Infraestructura De Datos Espaciales, Inteligencia Artificial Geoportales Y Computación Aplicada IDEIAGEOCA, Instituto Geográfico Militar, Av. Seniergues y Gral. Telmo Paz y Miño, Quito, Ecuador

*Autor para correspondencia: gnavas@ups.edu.ec

\section{Resumen}

Uno de los parámetros que más influyen en la pobreza es la mala calidad en la educación. El estudio sistemático de la pobreza es fundamental para mejorar la aplicación de planes y proyectos. En el Ecuador, a partir del año del 2005 inicia el "Proyecto para mejorar las condiciones de escolaridad, el acceso y la cobertura de la educación" en zonas de alto índice de pobreza a través del Gobierno Nacional (Ministerio de Educación, 2016). Este estudio realiza un análisis espacial de dicho proyecto gubernamental del Ecuador mediante el uso del software libre. Dicho análisis se fundamenta en la existencia de las instituciones educativas públicas denominadas "Unidades Educativas del Milenio" (UEM), cuyo fin es mejorar la calidad académica, satisfacer la demanda estudiantil rural y atender a sectores históricamente relegados, partiendo de 57 unidades educativas operativas en el año 2016 y utilizando técnicas de análisis espacial estadístico, apoyados en una base de datos relacional robusta como es el caso de PostgreSQL, con el fin de determinar cuál es su área de afectación a la población, creando varios tipos de coberturas para identificar las parroquias y el porcentaje de pobreza que es atendido por este proyecto educacional, logrando determinar que existe un $77 \%$ y el $96 \%$ de UEM, en zonas de extrema pobreza.

Palabras clave: Análisis espacial estadístico, UEM, unidades educativas del milenio, análisis espacial, PostgreSQLPostGIS, pobreza. 


\begin{abstract}
One of the most influence parameters in poverty is the poor quality of education. The systematic study of poverty is essential to improve the implementation of plans and projects. Since 2005, Ecuador began the 'Project to improve education conditions, schooling access and coverage of education' on high poverty areas through the National Government (Ministerio de Educación, 2016). This study performs a Spatial Analysis of the above governmental project of Ecuador by the use of free software. This analysis is based in the existence of public educational institutions called 'Millennium Educational Units', whose purpose is to improve academic quality, meet rural student demand and serve historically relegated sectors. It is sought using statistical spatial analysis techniques, supported by a robust relational database such as PostgreSQL for determining their impact area on the population by creating various types of coverage to identify the parishes and the poverty percentage that is being benefited by this educational project, managed to determine that there is a percentage between $77 \%$ and $96 \%$ of UEM, located in areas of extreme poverty.
\end{abstract}

Keywords: Statistical Spatial Analysis, UEM, millennium educational units, spatial analysis, PostgreSQL-PostGIS, poverty.

Forma sugerida de citar: Navas, G.E., Llerena Paz, R. y Vaca, F. (2019). Análisis espacial de las unidades educativas del milenio en el Ecuador y su cobertura en zonas de pobreza. La Granja: Revista de Ciencias de la Vida. Vol. 30(2):121-133. http://doi.org/10.17163/lgr.n30.2019.10.

\title{
IDs Orcid:
}

Gustavo Ernesto Navas: https:/ / orcid.org/0000-0002-2811-0282

Robinson Llerena Paz: https://orcid.org/0000-0003-1512-2759

Fernando Vaca: https:/ / orcid.org/0000-0003-3375-2236 


\section{Introducción}

La UNICEF y en particular la Comisión Económica para América Latina y el Caribe (CEPAL) destacan la importancia del monitoreo sistemático de la pobreza para reducirla y lograr un país más equitativo (Unicef Ecuador, 2015). La educación en Ecuador ha carecido de un nivel académico de calidad en las poblaciones más pobres; en el 2005 se inicia el proyecto educativo Unidades Educativas del Milenio el cual pretende reducir esta brecha y llegar a niños y niñas de recursos económicos limitados (Ministerio de Educación, 2016).

Las Unidades Educativas del Milenio (UEM), es un proyecto de dotación de Institutos Educativos públicos de nivel primario y secundario que se creó para mejorar la educación del país y llegar a los sectores pobres, por tal razón sus edificaciones están ubicadas en sectores históricamente relegados a nivel nacional, que cuentan con altos índices de necesidades básicas insatisfechas y problemas sociales como la migración interna y externa, con instituciones educativas caracterizadas por la baja calidad educativa y por la ausencia de las condiciones mínimas para la formación de niñas, niños y jóvenes (Ministerio de Educación, 2016).

La primera UEM se construyó en el año 2008 en la parroquia de Zumbahua, ubicada en la provincia de Cotopaxi. Según información del Ministerio de Educación (1 noviembre 2013) hasta el año 2013 se construyeron 31 UEM, a un costo de USD 69'318.199,30, las cuales atienden a 23.282 estudiantes; y 33 UEM están siendo construidas (programa 'Nueva Infraestructura Educativa'). La página del Ministerio presenta información actualizada al 2015 donde se indica que hay 53 UEM en funcionamiento, 60 en construcción y 212 por construirse (Ministerio de Educación, 2016). Los Geoportales en el Ecuador han permitido tener un inventario georreferenciado de proyectos estatales como son: zonas de riesgo, reservas naturales y todo aquello que puede ser apreciado sobre un mapa (Navas y Prieto, 2011). La información de Geoportal del (Ministerio de Educación, 2016) fue la base del estudio realizado.

El 19 de enero del 2016 en la página del (Ministerio de Educación, 2016) se publica la noticia sobre la inauguración de la Unidad Educativa del
Milenio (UEM) Nueva Generación en la provincia de Morona Santiago. Este estudio está basado en el $89,8 \%$ de unidades educativas construidas hasta la fecha de la toma de datos en el año 2016. Las Unidades Educativas del Milenio son parte integral de la política gubernamental para mejorar la calidad de la educación pública. Cada UEM se construye para garantizar el acceso de la población escolar de las zonas rurales permanentemente excluidas de los servicios educativos (Ministerio de Educación, 2016). Las UEM se basan en varios criterios de ubicación para su construcción.

Para el estudio las principales son (Peñafiel Larrea, Freddy, 2014): a) localización del predio, el cual no debe estar ubicado en zonas de riesgo; además, debe estar ubicado en un sitio de fácil acceso para la población; y de preferencia, debe estar localizado cerca de áreas verdes de uso público y áreas recreativas; b) accesibilidad al predio: deberá contar con infraestructura vial de primer, segundo y tercer orden; asimismo, deberá brindar condiciones de fácil acceso para los vehículos de servicio de emergencia, bomberos, transporte de pasajeros, recolectores de basura e ingreso de insumos; y de preferencia, deberá contar con dos vías de acceso claramente definidas. Finalmente, c) el área del terreno es de 2,2 hectáreas, equivalente a 22.000 metros cuadrados.

En el presente trabajo se plantea un método que ha permitido medir la cobertura de pobreza que tiene cada una de las UEM, empleando herramientas de software libre y técnicas de análisis espacial estadístico; de igual forma, permite observar la relación con las parroquias pobres del Ecuador, utilizando técnicas propuestas por el modelo (Bertolotto y McArdle, 2011) que incluyen el uso de herramientas de análisis espacial de software libre PostgreSQL - PostGIS y del visualizador web Open layer, utilizado por los mapas de Geoserver para mostrar los resultados obtenidos.

La representación de las propiedades geométricas de objetos espaciales, así como sus estructuras son cruciales para operaciones GIS, análisis y visualización (Groger y Betsy, 2012). Los tipos de datos espaciales se refieren a formas tales como puntos, líneas y polígonos (Boundless Server, 2012), los datos en sí son elementos vectoriales, que pueden ser puntos, líneas y polígonos juntos con sus atributos, 
y estos pueden ser representados mediante gráficos de barras y pasteles que indican porcentajes o tendencias (Peters, 2012). Los datos de las entidades geográficas también pueden mostrarse con distribuciones espaciales (Fu y Jiulin, 2011), para lograrlo los datos se han almacenado en una base de datos PostgreSQL con su extensión espacial PostgreSQLPostGIS. El análisis espacial tiene múltiples aplicaciones en la salud, agricultura, defensa, seguridad, catastros, planificación, servicios de localización, transporte, geología, energía, y utiliza diversos formatos para la gestión de la información como son: XML, GeoJson, Xslt, entre otros (Shklar y Rich, 2011; Babar, 2010; Ayen López, 2012). El análisis espacial se genera a través de una serie de operaciones tales como superposición de capas, uniones, intersecciones espaciales, operación de borrado y análisis de proximidad (Martínez Llario, 2013).

Para el presente trabajo se han empleado básicamente operaciones de unión, intersección y buffer, que por medio de sentencias especializadas en el manejo de geometrías de puntos y polígonos y con la ayuda de herramientas estadísticas se puede llegar a comprobar si las UEM están situadas en las parroquias más pobres del Ecuador y determinar qué porcentaje del nivel de pobreza se cubre por cada parroquia. Existen muchas herramientas que permiten ejecutar cada una de las operaciones antes mencionadas, por ejemplo, ArcGIS y MapInfo, que son aplicaciones pagadas cuyo costo es elevado y QGis que es una aplicación libre.

La ventaja de usar una base de datos relacional como PostgreSQL con su extensión PostGIS radica en que no se requiere ingresar a la interfaz gráfica de la aplicación GIS, que amerita conocimiento específico de la herramienta por parte del usuario. Una base de datos relacional permite ingresar directamente la información y las operaciones que se requieren ejecutar, la misma que al estar enlazada con la aplicación gráfica, posibilita que se visualice el resultado en forma transparente para el usuario. Adicionalmente el registro de nueva información en la base de datos no impide que todas las operaciones establecidas sigan siendo aplicables al nuevo universo de datos.

La utilización de una base de datos relacional, nos permite potenciar el uso de las herramientas que disponen estos programas tecnológicos de aná- lisis espacial; un ejemplo es obtener la ubicación geográfica que tienen estas Unidades Educativas, además identificar cuáles y qué tipo de poblaciones se verán beneficiadas.

\subsection{Descripción de datos}

Los sectores pobres se encuentran localizados en el mapa socio económico del Ecuador, donde se presentan índices de pobreza por cada parroquia, esta información fue obtenida de la página web de la Universidad del Azuay (Universidad del Azuay, 2018) (http://gis.uazuay.edu.ec/). La medición de pobreza requiere una previa definición conceptual de aquella realidad social que se pretende medir, por lo que existen varios indicadores o índices de pobreza que remiten ineludiblemente a los paradigmas o enfoques de la pobreza, como son el índice GINI, y el índice de las necesidades básicas insatisfechas (NBI) que sirve para identificar las carencias críticas de necesidades elementales como educación, salud y vivienda.

El índice de GINI (Economipedia, 2018), es una medida de carácter económico para calcular la desigualdad de ingresos existente entre los habitantes del área de estudio; normalmente se utiliza para medir la desigualdad en los ingresos dentro de un país, pero puede utilizarse para medir cualquier forma de distribución desigual. El coeficiente de Gini es un número entre 0 y 1 , en donde 0 se corresponde con la perfecta igualdad (todos tienen los mismos ingresos) y donde el valor 1 se corresponde con la perfecta desigualdad (una persona tiene todos los ingresos y los demás ninguno) (Damm, 2013).

El NBI es un método directo para identificar carencias críticas en una población y caracterizar la pobreza utilizando cuatro áreas de necesidades básicas de las personas (vivienda, servicios sanitarios, educación básica e ingreso mínimo), disponibles en los censos de población y vivienda realizados por el INEC (INEC, 2010), y se ha considerado como el índice más apropiado para este estudio; siendo también el método implementado por la Comisión Económica para la América Latina (CEPAL) (INEC, 2017).

La información ofrecida por el INEC tiene datos de los porcentajes de pobreza de cada parroquia tabulados en un archivo de Excel, pero sin datos geo- 
espaciales, a diferencia de los datos obtenidos de la página web de la Universidad de Azuay, en donde los datos de pobreza son representados por el índice GINI para cada parroquia que cuenta con sus respetivas coordenadas geográficas, guardados en un archivo de tipo shapefile. Para poder tener una tabla con índices NBI y la ubicación geográfica por parroquia se realizó una fusión de las dos tablas antes mencionadas, para lo cual se desarrolló una consulta PostgreSQL-PostGIS que enlaza estas dos tablas por medio del nombre de parroquias, cantones y provincias. El resultado obtenido en esta consulta fue del $60 \%$ del total de las parroquias, donde el $40 \%$ restante fue elaborado de manera manual. El fragmento de código indicado a continuación es una consulta SQL a la base de datos para enlazar los resultados.

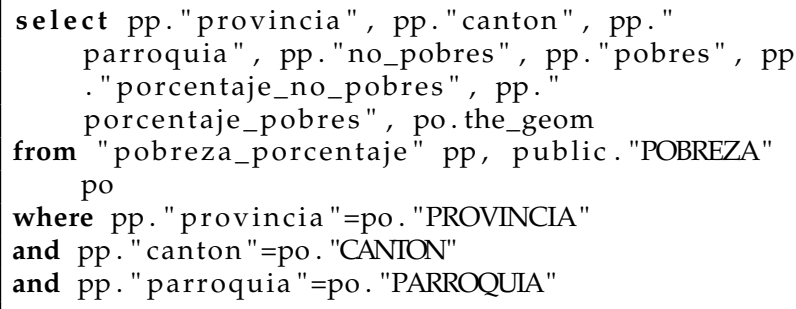

La información y posición de las UEM fueron descargadas del geoportal del Ministerio de Educación, (2016) en extensión KML; las coordenadas obtenidas están en el sistema de coordenadas geográfico mundial WGS84 cuya equivalencia es el código EPGS: 4326. El WGS84 (World Geodetic System 1984) es un datum de cobertura global de todo el planeta Tierra y es el más comúnmente usado en la actualidad (Westra, 2013). En definitiva, para este análisis es necesario obtener dos tablas de datos, la primera que contiene la información de pobreza a nivel de parroquia, que es el producto de la fusión de los datos de la universidad del Azuay y del INEC, y la segunda tabla que corresponde a la ubicación geoespacial de las UEM.

\subsection{Metodología}

Los datos utilizados para el estudio fueron obtenidos del Geoportal del Ministerio de Educación, (2016) el cual despliega 53 coordenadas geográficas que representan la posición de cada establecimiento educativo. Para identificar si las UEM se encuentran en las zonas más necesitadas del país se realizó un análisis espacial con sentencias PostgreSQLPostGIS. El análisis espacial es un conjunto de mé- todos cuyos resultados cambian cuando las localizaciones de los objetos analizados también cambian (Huang, Li y Gartner, 2011). La diferencia entre una base de datos y una base de datos espacial son los datos espaciales que representan elementos geográficos. Estos datos espaciales abstraen y encapsulan estructuras espaciales como límites y dimensiones. Se estableció un área uniforme de estudio alrededor de cada unidad educativa $(5,10$ y $20 \mathrm{Km})$, para realizar un muestreo y poder cuantificar el nivel de pobreza de las personas que asisten a estas instituciones educativas, ya que identificar y precisar la cobertura de los estudiantes que asisten a cada UEM es una tarea muy compleja debido a que la población del Ecuador se encuentra situada en varios sitios dispersos del país. Para poder realizar este cálculo se repartió la superficie a ser considerada como cobertura de cada establecimiento con la mayor eficacia posible respecto a los diferentes centros existentes que son las coordenadas de las UEM (Peter, 1977), en donde el movimiento desde el centro de cada área hasta sus sectores periféricos debe ser mínimo (Buzai, 2011).

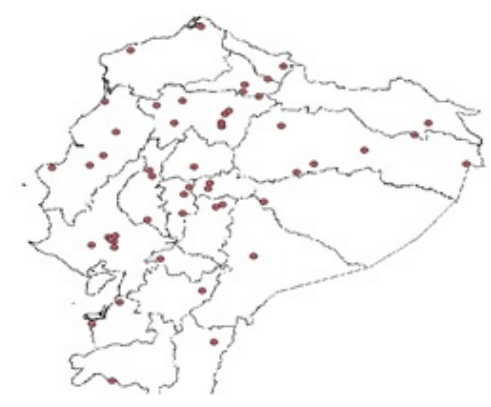

Figura 1. Mapa de la ubicación de la UEM en un área de influencia circular de $5 \mathrm{Km}$.

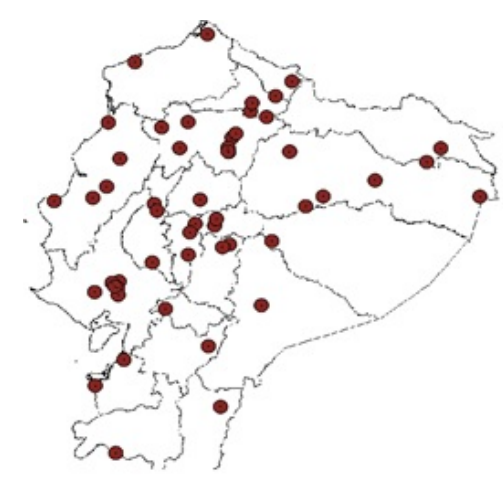

Figura 2. Mapa de la ubicación de UEM en un área de influencia circular de $10 \mathrm{Km}$. 
En su estudio Buzai, (2011), establece que los polígonos regulares brindan mejores resultados que los polígonos irregulares, y que el círculo es el polígono regular de mayores condiciones deseables. El área de influencia circular es un método de aproximación sencilla y fácil de implementar, pero se debe tomar en cuenta que esta metodología no considera la existencia de barreras, ni la red vial que es por donde normalmente se desplazan los estudiantes; en este tipo de análisis se recomienda que el área circular tenga un radio de $0.5 \mathrm{~km}$ en área urbana, tomando en cuenta que una persona se demora en trasladarse a pie de 5 a 10 minutos y en el área rural se puede incrementar considerablemente, ya que la posibilidad de solapamiento entre establecimientos es baja (Córdoba, 2012).



Figura 3. Mapa de la ubicación de UEM en un área de influencia circular de $20 \mathrm{Km}$.

En este estudio no se clasificaron como rurales o urbanas a las zonas en donde se encuentran localizadas las UEM, por tal razón se las analizó de manera homogénea, generando para todas y cada una de las UEM tres coberturas circulares diferentes con radios de 5, 10 y $20 \mathrm{Km}$ a la redonda, tomando en cuenta que el tiempo en trasladarse es aproximadamente de 5 a $30 \mathrm{~min}$ en transporte público. Cabe mencionar que la ordenanza municipal de Quito también considera áreas circulares en donde se dispone que los estudiantes deben vivir dos kilómetros a la redonda de los planteles educativos en zona urbana (Secretaría de Educación y Deporte, 2015). Las Figuras 1, 2 y 3 muestran el perfil del Ecuador político dividido por provincias y la ubicación de cada unidad educativa del milenio, donde las UEM están representadas por puntos generados en el sistema de coordenadas geográfico mundial WGS84, cuya equivalencia es el código EPGS:4326, que son los centroides de cada área circular de 5,10 y $20 \mathrm{~km}$ de radio respectivamente, que tienen como fin indicar el área de cobertura de cada unidad educativa.

Para este proceso de análisis también se ha tomado en cuenta otra ordenanza de los centros educativos municipales en la ciudad de Quito con respecto al sector rural, considerando que el estudiante deberá residir dentro de la parroquia en la cual está situado el establecimiento educativo (Secretaría de Educación y Deporte, 2015). Los resultados de pobreza de cada estudio con los diferentes parámetros que se ha sometido a la cobertura que tienen las UEM con respecto a la población, ayudarán a responder la interrogante de esta investigación, sobre si los establecimientos educativos en cuestión están ubicados en zonas pobres del Ecuador. Las coberturas estarán separadas por áreas de influencia circular con radios de 5, 10 y $20 \mathrm{~km}$, se profundizará su estudio en el análisis de área circular y por áreas de influencia a nivel parroquial, y estas serán analizadas en los siguientes apartados.

\subsection{Análisis por área circular}

Para este análisis se realizó una intersección en PostgreSQL - PostGIS, entre las áreas circulares de las UEM y el mapa de pobreza como se indica en la Figura 4. Esta intersección indica la cobertura que tiene cada una de las UEM con respecto a las parroquias que se encuentran en el mapa de pobreza. El mapa resultante muestra circunferencias divididas en varios segmentos; estos segmentos son el área que abarca cada parroquia con respecto al área de influencia circular de cada UEM. Cada segmento cuenta con dos datos importantes, el porcentaje de área de la intersección entre la parroquia y la UEM y el porcentaje de pobreza que tiene cada parroquia a la que pertenece.

El área de influencia de cada UEM cubre a varias parroquias con diferentes porcentajes de pobreza. Cada fragmento de parroquia dentro de la circunferencia ha sido ponderado a razón del valor de su área, facilitando así el uso de la media ponderada, que es el promedio de cantidades a las cuales se ha asignado un coeficiente, denominado peso, para tener en cuenta adecuadamente su importancia relativa.

La media ponderada de un grupo de datos $X_{1}, X_{2}, \ldots, X_{n}$, con sus correspondientes pesos $W_{1}, W_{2}, \ldots, W_{n}$ puede obtenerse a través de la fórmula 
(1) $(\mathrm{Paz}, 2007)$.

$$
\overline{X_{w}}=\frac{\sum_{i=1}^{n} X_{i} W_{i}}{\sum_{i=1}^{n} W_{i}}
$$

Asimismo, para conocer el índice de necesidades básicas insatisfechas (INBI) por cada centro educativo se calculó la media ponderada con los datos obtenidos de la intersección, las tablas de datos geoespaciales de pobreza y la ubicación de UEM realizada con una consulta PostgreSQL - PostGIS en donde se analiza a profundidad el cálculo de la pobreza por cobertura circular.

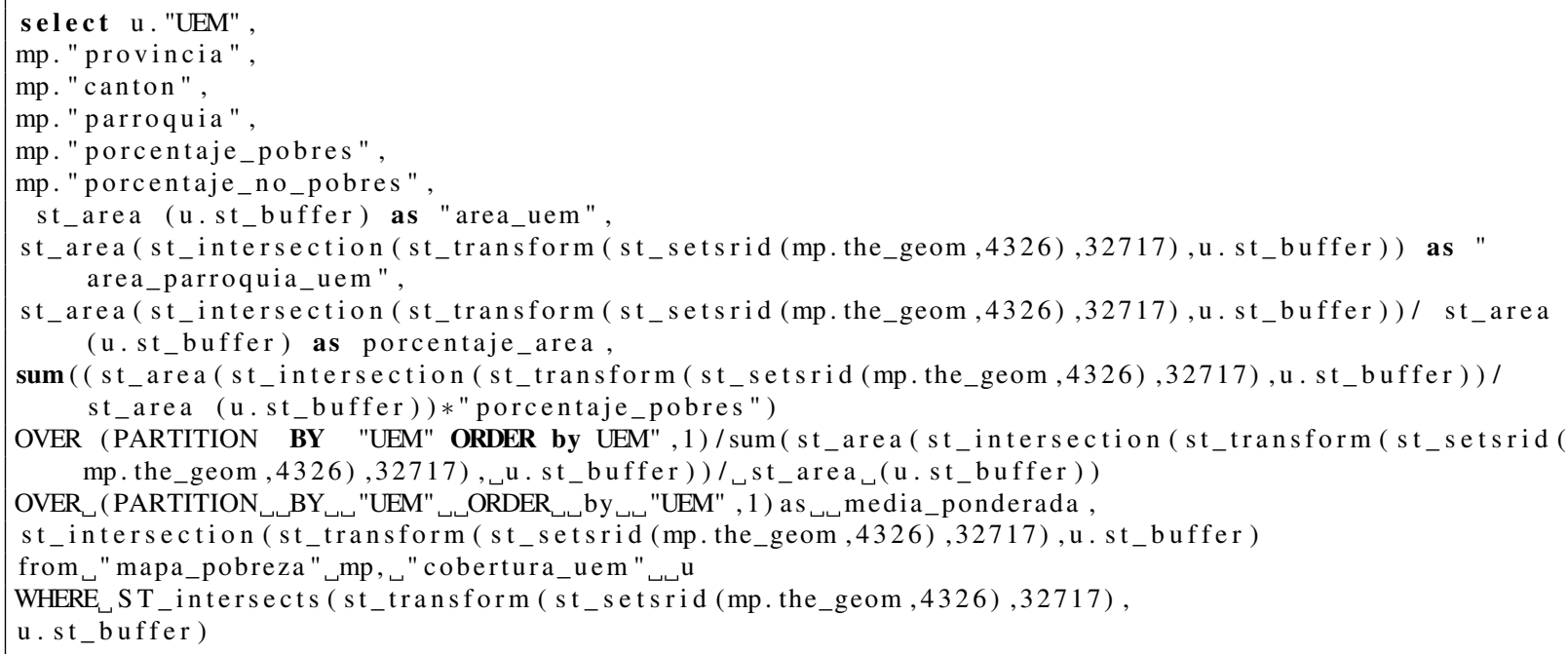

Tabla 1. Consulta PostGIS para obtener la pobreza por cobertura circular.

\subsection{Cálculo de la pobreza por cobertura circular}

La función st_buffer es utilizada para obtener el polígono circular alrededor del punto que representa a los establecimientos educativos. Esta arroja una geometría que envuelve al objeto con una distancia establecida a la geometría de entrada, en este caso la geometría resultante será un circulo que representa el área de influencia circular alrededor de la UEM. El análisis por área circular se centra en realizar una intersección entre polígonos circulares que representa la cobertura de las UEM y los polígonos de las parroquias contenidos en la tabla de pobreza del Ecuador; es decir, que el resultado de este estudio se basa en el análisis espacial que se realizó entre dos geometrías de tipo polígono.

Posteriormente con los datos obtenidos se calculó la media ponderada, cuyos pesos están dados por cada área resultante de la intersección. Este análisis se consiguió con el código que se muestra a continuación en la Tabla 1. Las columnas resultantes de la consulta antes mencionada son el nombre de la UEM, la provincia, cantón, parroquia y el porcentaje de pobreza de cada parroquia. Estos primeros datos fueron obtenidos directamente de sus tablas correspondientes. A continuación, se detallan los siguientes datos con sus respectivas sentencias.

En la Figura 4 se puede apreciar que la cobertura de la UEM es el circulo de color rojo que es definido como el área de influencia circular. Para determinar la superficie de esta figura con sus respectivos radios de 5, 10 y $20 \mathrm{~km}$ se usa el código que se indica a continuación, cabe recalcar que en esta sección solo se indica cómo obtener el área con radio de $10 \mathrm{~km}$, ya que para 5 y $20 \mathrm{~km}$ se debe cambiar el valor en la función st_buffer de la sentencia, para el uso de esta función, el radio se debe transformar en metros:

Primero se crea la tabla en la Base de Datos:

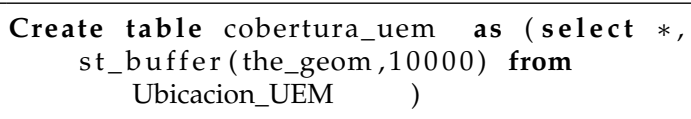


Como siguiente paso se utilizó la tabla creada para calcular el área circular.

select area(st_buffer)

Para el área de intersección entre la cobertura UEM y las parroquias, primero se calcularon las coordenadas del contorno de la intersección, es decir la geometría (the_geom), con la función st_intersection para posteriormente realizar la transformación al sistema 32717 y obtener el área con la función st_area, donde el código es el siguiente:

Select st_intersection(st_transform(st_setsrid( mp.the_geom,4326), 32717), u.st_buffer) from "mapa_pobreza" mp, "cobertura_uem" $u$

El porcentaje de área se calculó dividiendo las dos áreas anteriores, es decir:

st_area(st_intersection (st_transform (st_setsrid (mp.the_geom,4326),32717), u.st_buffer))/ st_area (u.st_buffer) as porcentaje_area,

Cada UEM debe tener su porcentaje de pobreza en relación de los datos de pobreza de las parroquias que la intersecan, por lo que es necesario calcular la media ponderada de cada UEM, para lo cual se debe ordenar y particionar la consulta para realizar la sumatoria del producto entre el valor de cada porcentaje de pobreza $\left(X_{i}\right)$ de cada parroquia por la superficie que cubre el área circular a cada parroquia que interseca, este valor es el peso $\left(W_{i}\right)$ que se le da al valor $\left(X_{i}\right)$.

Por lo tanto, la consulta PostgreSQL-PostGIS para definir la Ecuación (1) viene dada por el siguiente código:

sum((st_area(st_intersection (st_transform (
st_setsrid (mp.the_geom,4326),32717), u.
st_buffer))/ st_area (u.st_buffer))*"
porcentaje_pobres") over (PARTITION BY "
UEM" ORDER by "UEM",1)/sum(st_area (
st_intersection (st_transform (st_setsrid (mp.
the_geom,4326),32717), u. st_buffer))/
st_area (u.st_buffer)) OVER (PARTITION BY
"UEM" ORDER by "UEM",1) as media_ponderada,
st_intersection (st_transform ( st_setsrid (mp.
the_geom,4326),32717), u.st_buffer)

\subsection{Análisis por parroquia}

Para este análisis se tomó en cuenta que el área de influencia está dada por los límites de la parroquia a la que pertenece la UEM, por tal razón el porcentaje de pobreza que cubre cada UEM está dada por el índice de NBI de la parroquia en donde se encuentra ubicada. Al igual que en el análisis anterior, se utilizó el mapa de pobreza y la ubicación puntual de cada UEM.

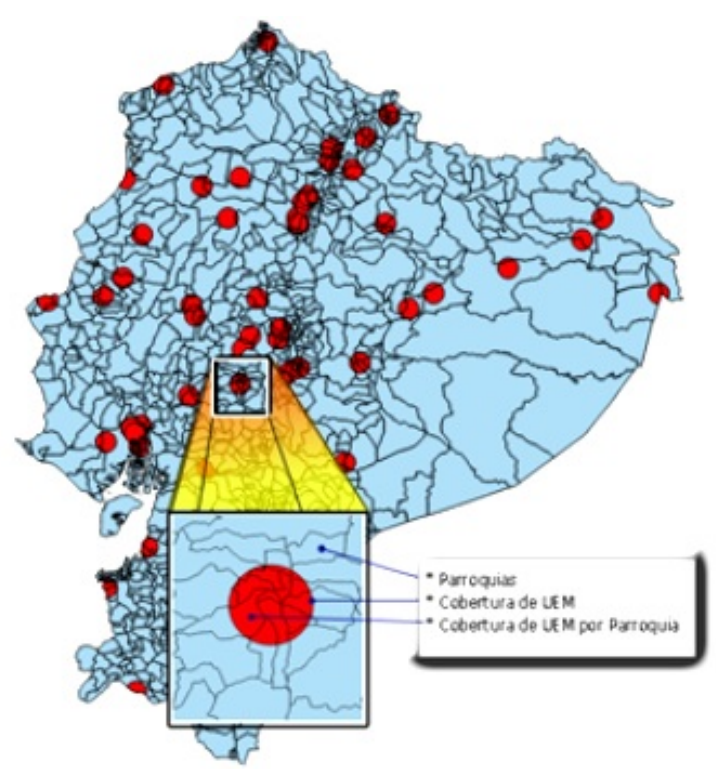

Figura 4. Mapa de las áreas que cubren las UEM en cada parroquia del Ecuador. 


\subsubsection{Cálculo de la pobreza por cobertura de parro- quia}

Primero se realizará una evaluación para verificar cuales puntos pertenecen a la ubicación de las UEM contenidas en los polígonos irregulares que repre- sentan a la parroquia, esto se logra gracias a la sentencia St_contains, que es la que determina si una geometría está totalmente dentro de otra. La sentencia PostgreSQL-PostGIS utilizada en este caso es la siguiente.

CREATE TABLE UEM_PARROQUIAS AS ( select u. "UEM", mp."provincia" , mp."canton" , mp."parroquia" , mp. "porcentaje_pobres", mp.the_geom

from mapa_pobreza $\mathrm{mp}$, ubicacion $\mathrm{u}$

where st_contains (mp.the_geom, st_setsrid (u.the_geom,4326)))

\subsection{Visor geoespacial}

Para que estos resultados sean fácilmente legibles y entendibles se ha construido un visor geográfico con la ayuda de los programas mencionados anteriormente, los cuales son parte de OpenGeo suite (Boundless Server, 2012) que es un kit de desarrollo de Software (SDK) libre que proporciona las siguientes herramientas:

\subsubsection{PostgreSQL-PostGIS}

Como ya se mencionó PostgreSQL-PostGIS es una extensión de PostgreSQL que permite almacenar información de mapas y realizar análisis espaciales entre puntos, líneas, polígonos y otras formas geométricas (Boundless, 2012).

\subsubsection{GeoServer}

Es un servidor web que puede servir aislado o bien sobre un contenedor de aplicaciones Tomcat o similar. GeoServer tiene una interfaz de administración web que permite servir mapas y datos de diferentes formatos para aplicaciones Web o de escritorio como son los GIS.

\subsubsection{OpenLayers}

Es una librería de código abierto en javascript para hacer mapas interactivos, visibles fundamentalmente en entornos Web, que es capaz de conectarse con GeoServer (o con otras fuentes de mapas, como google maps), para presentar en un navegador las capas de un servidor de mapas/datos. Ofrece una interfaz de usuario simplificado que ataca a servicios WMS y WFS de forma transparente para el usuario y desarrollador (Morales, 2012; Hazzard, 2011; Perez, 2012). Cada uno de estos componentes realizan un trabajo específico que se une bajo un esquema como se indica en la Figura 5 para llegar a tener una aplicación web de mapas.



Figura 5. Esquema del visualizador geográfico.

\section{Resultados}

Los datos expuestos en la Tabla 1 son el resultado del primer análisis donde se muestra el número de UEM que pertenece a cada rango de porcentajes de pobreza, y al área de influencia de los establecimientos educativos para los estudiantes que viven dentro de la zona circular de 5, 10 y $20 \mathrm{Km}$ de radio, 
incluyendo el análisis en el cual solo la población de la misma parroquia en donde se encuentra construida la UEM podrá ser beneficiada.

Si se toma como punto medio el $50 \%$ de pobre$\mathrm{za}$, en la Tabla 2 se puede apreciar que los rangos que están por encima a este valor abarcan más del $70 \%$ de UEM en todas las áreas de influencia, indicando que la mayor parte de estos establecimientos están construidos en zonas de pobreza y pobreza extrema. Se puede apreciar también una total ausencia de UEM en zonas donde la pobreza es menor al 25\%. La Tabla 2, indica el porcentaje de UEM que están en las diferentes coberturas en rangos de $25 \%$ de pobreza. En donde se puede observar que:

- En los cuatro tipos de coberturas no se encuentra ninguna UEM en pobreza menor al $25 \%$.

- En las cuatro coberturas el porcentaje de UEM aumenta mientras el porcentaje de pobreza es mayor.

- Existe una cantidad importante de UEM en rangos mayores al $75 \%$ de pobreza.

Los porcentajes son de $81 \%, 81 \%, 96 \%$ y $77 \%$, respectivamente, considerando un universo de 53 UEM, tomando además como punto medio al $50 \%$ y realizando una sumatoria entre los rangos de $50 \%$ $75 \%$ y $75 \%-100 \%$ con cada área de cobertura circulares de 5, 10, $20 \mathrm{~km}$ y por parroquias; por tal razón se tomarán en consideración los porcentajes de pobreza mayores a $50 \%$ divididos en quintiles de $10 \%$, para identificar la cantidad de establecimientos educativos por cada rango de pobreza. Al tener correctamente estructurada la data en una base de datos relacional se garantiza la consistencia de los datos y por ende de los resultados obtenidos.

Con la finalidad de facilitar el estudio se dividen los niveles de pobreza por quintiles denominadas como: baja (50\%-60\%), media baja $(60 \%-70 \%)$, media $(70 \%-80 \%)$, alta $(80 \%-90 \%)$ y muy alta $(90 \%-$ $100 \%)$. La distribución de los centros educativos en pobrezas mayores a $50 \%$ son más equitativos, sin embargo, en la Figura 6 se indica una tendencia que va de la pobreza media alta en adelante.

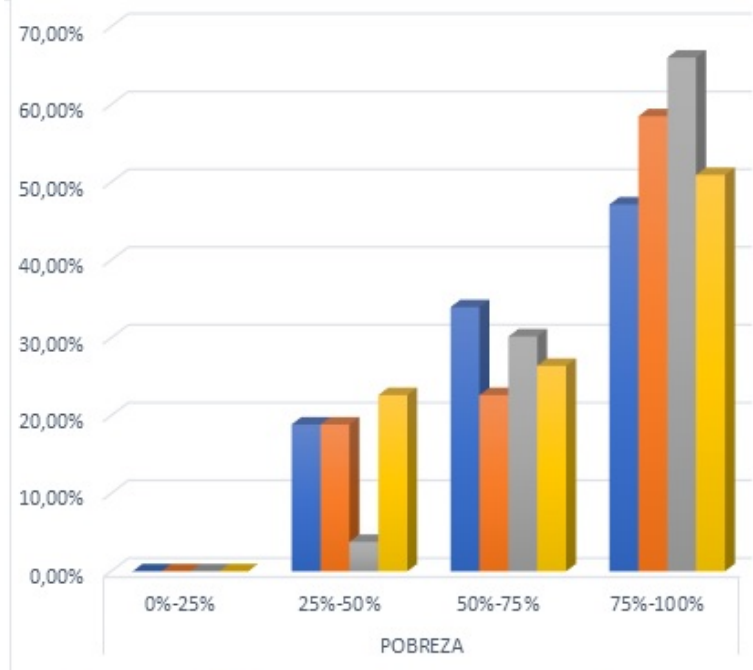

a Circular de $5 \mathrm{Km}$ a Circular de $10 \mathrm{Km}$ a Circular de $20 \mathrm{Km}$ a Por parroquia

Figura 6. Porcentaje de UEM en rangos de pobreza.

Se puede apreciar en la Figura 7, que en las UEM en las cuatro áreas de cobertura los valores tienden a las zonas con pobreza media, aumentando en los tres primeros casos a la pobreza alta y muy alta. El nivel de pobreza más bajo que cubre una UEM pertenece al centro educativo Réplica Montufar ubicado en la parroquia Quito, cantón Quito, provincia Pichincha con el 34,16\%; y el nivel más alto es el de la UEM Chontapunta ubicado en la parroquia Chontapunta, cantón Tena, provincia de Napo, con el $99,61 \%$ de pobreza.



Figura 7. Cantidad de UEM que cubre los rangos de pobreza mayores al $50 \%$. 


\begin{tabular}{lcccc} 
COBERTURA UEM & $\begin{array}{c}\text { Porcentaje INBI } \\
\text { de POBREZA } \\
\mathbf{0 \% - 2 5 \%}\end{array}$ & $\begin{array}{c}\text { Porcentaje INBI } \\
\text { de POBREZA } \\
\mathbf{2 5 \% - 5 0 \%}\end{array}$ & $\begin{array}{c}\text { Porcentaje INBI } \\
\text { de POBREZA } \\
\mathbf{5 0 \% - 7 5 \%}\end{array}$ & $\begin{array}{c}\text { Porcentaje INBI } \\
\text { de POBREZA }\end{array}$ \\
\hline 75 \%-100 \% \\
\hline Circular de 5 Km & 0 & 10 & 18 & 25 \\
Circular de 10 Km & 0 & 10 & 12 & 31 \\
Circular de 20 Km & 0 & 2 & 16 & 35 \\
Por parroquia & 0 & 12 & 14 & 27 \\
\hline
\end{tabular}

Tabla 2. Cantidad de UEM en rangos de pobreza por área de cobertura.

La mediana calculada en este conjunto de datos (Figura 8) corresponde al 76,65\% (color naranja), cuyo valor pertenece a la UEM Paiguara, indicando que 26 unidades educativas están sobre este valor y 26 unidades educativas tienen valores inferiores a la mediana. El gráfico de la distribución de frecuencias de la Figura 9 tiene un sesgo a la derecha, lo que indica que la mediana es mayor al promedio; razón por la cual se puede deducir que la mayor parte de UEM tienden a estar ubicadas en los sectores más pobres del país. En otras palabras, el valor de la media aritmética es del 74,29\% (color verde), que indica que el promedio que cubren las unidades educativas en este estudio está sobre el $50 \%$ de pobreza.



Figura 8. Porcentaje de UEM en quintiles por cobertura de pobreza.

\section{Conclusiones}

Con los métodos de intersección de polígonos en PostgreSQL-PostGIS y utilizando métodos matemáticos se ha demostrado que el $84 \%$ de las UEM construidas hasta el momento están en zonas donde sus necesidades básicas insatisfechas están por encima del $50 \%$.

Se ha podido deducir bajo varios puntos de vista de áreas de influencia, como son las circulares con radios variables de 5,10 y $20 \mathrm{~km}$ y polígonos irregulares como son las áreas de las parroquias de cada UEM a la que pertenece, que las unidades educativas mencionadas en este estudio están construidas en áreas rurales y satisfacen a la población más necesitada.

En el análisis individual de cada UEM se puede concluir que por encima de la media aritmética de pobreza se encuentran 33 unidades educativas con rangos mayores a 74,29\%, siendo la UEM Chontapunta el establecimiento que se encuentra en una zona donde su índice de NBI es del 99,61\%, ubicada en la provincia de Napo, región amazónica. Y por debajo de la media existen 21 establecimientos, siendo el centro educativo Réplica Montufar ubicado en la parroquia Quito, cantón Quito, provincia Pichincha con el $34,16 \%$ la UEM que cubre el nivel más bajo de pobreza. 




Figura 9. Porcentaje de pobreza que cubre cada UEM.

\section{Referencias}

Ayen López, José A. (2012). Catastro y nuevas tecnologías. Inf. téc. Saaerbrucken: Lap Lambert Academic Publishing GmbH \& Co.

Babar, Shahzad (2010). Accessibility of Web based GIS applications. Inf. téc. Saaerbrucken: Lap Lambert Academic Publishing AG \& Co.
Bertolotto, Michela y Gavin McArdle (2011). «Data reduction techniques for web and mobile GIS». En: Advances in Web-based GIS, Mapping Services and Applications 9, pág. 139.

Boundless Server (2012). Introduction Boundless Server. URL: http : / / suite . opengeo . org / docs / latest/intro/index.html.. 
Boundless (2012). PostGIS. último acceso: 04 de 09 de 2015. URL: http:/ / workshops.boundlessgeo. com/postgis-intro/introduction.html.

Buzai, Gustavo D. (2011). «Geografía y Sistemas de información geográfica». En: Revista Geográfica de América Central, 15-67. Online:https:/ / bit.ly / 2Ni3SN6.

Córdoba, Guillermo (2012). Áreas de influencia, tipos $y$ aplicaciones en geomarketing. último acceso: 12 de 01 de 2015. URL: http:/ / www.unica360.com/ areas - de-influencia - tipos - y - aplicaciones - engeomarketing.

Damm, Arturo (2013). Thatcher y el coeficiente de Gini.

Economipedia (2018). Índice de GINI.

Fu, Pinde y Sun Jiulin (2011). «WebGIS Principles and applications». En: Esri Press.

Groger, Gerhard y George Betsy (2012). «Handbook of Geographic Information». En: ed. por Wolfgang Kresse y David Danko. Springer. Cap. Geometry and Topology, págs. 303-321.

Hazzard, Erik (2011). Openlayers 2.10 beginner's guide. Packt Publishing Ltd.

Huang, Haosheng, Yan Li y Georg Gartner (2011). «A load balancing method to support spatial analysis in XML/GML/SVG-based WebGIS». En: Advances in Web-based GIS, mapping services and applications, págs. 153-168.

INEC (2010). Población: Necesidades básicas insatisfechas total nacional. Inf. téc. Instituto Nacional de Estadística y Censos. Online: https: / / bit.ly / 2xTLcuj.

- (2017). Reporte de Pobreza y Desigualdad. Inf. téc. Instituto Nacional de Estadística y Censos. Online: https:/ / bit.ly/2FnRsRb.

Martínez Llario, José Carlos (2013). «PostGIS 2. Análisis espacial avanzado». En:
Ministerio de Educación (2016). Visualizador Geográfico.

Ministerio de Educación (2016). Proyecto emergente de Unidades Educativas del Milenio y Establecimientos Réplica.

Morales, Aurelio (2012). Las mejores aplicaciones GIS open source.

Navas, Gustavo y Patsy Prieto (2011). «Geoportales en el Ecuador». En: La Granja, 58-64. Online: https://bit.ly/2Zfbzdb.

Paz, Inga Karim (2007). «Media Aritmética simple». En: Boletín Electrónico 7, 1-13. Online: https: / / bit.ly/2KUgojd.

Peñafiel Larrea, Freddy, ed. (2014). Acuerdo Nro. MINEDUC-ME-2014-00034- $A$. Ministerio de Educación del Ecuador. Online: https : / / bit . ly/2Mrd3LM.

Perez, Santiago (2012). OpenLayers Cookbook. Packt Publishing Ltd.

Peter, Hagget (1977). Análisis Locacional en Geografía Humana. Ed. gustavo Gili.

Peters, Dave (2012). Building a GIS. Inf. téc. Redlands: Esri Press.

Secretaría de Educación y Deporte (2015). Secretaría de Eduación y Deporte. Inscripciones Instituciones Municipales. Secretaría de Eduación y Deporte.

Shklar, Leon y Rosen Rich, eds. (2011). Web Application Architecture. Chichester. Online: https://bit. ly/2ZocEQl: John Wiley \& Son Ltd.

Unicef Ecuador (2015). Pobreza y pobreza infantil multidimensional.

Universidad del Azuay (2018). Infraestructura de Datos Espaciales. UDA.

Westra, Erik (2013). Python Geospatial Development. Packt Publishing Ltd. 